\title{
GAAP, GFS and AASB 1049: perceptions of public sector stakeholders
}

\author{
Ralph Kober ${ }^{\mathrm{a}}$, Janet Lee ${ }^{\mathrm{b}}$, Juliana $\mathrm{Ng}^{\mathrm{b}}$ \\ ${ }^{a}$ Department of Accounting and Finance, Monash University, Caulfield East, VIC, \\ Australia \\ ${ }^{\mathrm{b}}$ The Australian National University, School of Accounting and Business Information Systems, \\ The Australian National University, Canberra, ACT, Australia
}

\begin{abstract}
Efforts by Australian standard-setters to harmonise public sector financial reporting resulted in $A A S B$ 1049, which sought to bridge the divide between generally accepted accounting principles (GAAP)-based and government finance statistics (GFS)-based financial statements. However, whether AASB 1049 has resulted in information that is considered appropriate for the public sector has not been examined. We explore this issue by comparing the requirements of $A A S B 1049$ with the responses from a survey of public sector stakeholders on the appropriate accounting treatment and presentation of selected financial items. The analysis suggests consensus with AASB 1049 on presentation issues but less consensus on accounting treatments.
\end{abstract}

Key words: Accrual accounting; General government sector; Government finance statistics; Harmonisation; Public sector

JEL classification: M41, M48

doi: $10.1111 / \mathrm{j} .1467-629 X .2012 .00469 . \mathrm{x}$

Financial support from an AFAANZ research grant for this project is gratefully acknowledged. The authors wish to express their appreciation to the Associate Editor Professor Gary Monroe and the anonymous reviewer for their helpful and constructive comments. The authors also wish to thank participants at the 2011 Public Sector Accounting Workshop (The Australian National University, Canberra, ACT) for their comments.

[Note: Corrections have been made to the article title, and some small corrections have been added to the Abstract, Key words and Acknowledgements on 26 March 2012, after first online publication on 24 January 2012.]

Received 12 January 2011; accepted 24 December 2011 by Gary Monroe (Deputy Editor).

(C) 2012 The Authors

Accounting and Finance (c) 2012 AFAANZ 


\section{Introduction}

In 2007, the Australian Accounting Standards Board (AASB) released $A A S B$ 1049 Whole of Government and General Government Sector Financial Reporting. ${ }^{1}$ Prior to its introduction, public sector financial statements had to reflect two accounting frameworks, generally accepted accounting principles (GAAP)-based accrual accounting and government finance statistics (GFS)-based accrual accounting, which resulted in two sets of different financial values (Barton, 2007, 2009). AASB 1049 was an attempt to harmonise the GAAP and GFS systems, and the AASB's actions to narrow the gap between the two systems was aimed at reducing the confusion caused by having two sets of budget financial statements and better meeting the information needs of public sector stakeholders (Youngberry, 2010).

$A A S B 1049$ came into operation for reporting periods after 30 June 2008, but deviations exist in the federal government's practices for the preparation of budget financial statements. The reluctance to fully commit to this standard suggests unresolved issues with the appropriateness of $A A S B 1049$ for the public sector.

The appropriateness of financial information prepared under GAAP for public sector decision-making has been vigorously debated for many years, as has the use of GFS as an alternative system. However, whether the convergence of GAAP and GFS accounting treatments into AASB 1049 has resulted in information that is appropriate for public sector decision needs has not been examined. Our paper explores this question.

Specifically, our paper examines the extent to which the requirements of $A A S B$ 1049 align with public sector stakeholders' perceptions of appropriate accounting treatments and presentations for selected financial items. Because financial information is produced to meet the decision-making needs of those who use that information, any assessment of whether a particular accounting treatment is appropriate must necessarily include the views of those who have an interest in that information.

We undertake our analysis by comparing the responses from a survey of public sector stakeholders (i.e. officials from governing bodies, senior managers and CFOs of government departments) with the prescribed requirements of $A A S B$ 1049. The survey sought stakeholders' views on whether GAAP or GFS was the appropriate accounting treatment and presentation for a set of financial items for the general government sector. The comparison of survey responses with

\footnotetext{
${ }^{1}$ The whole of government sector encompasses the Commonwealth (federal) Government of Australia, the state governments within Australia (i.e. New South Wales, Queensland, South Australia, Tasmania, Victoria and Western Australia) and the governments of the territories within Australia (i.e. Australian Capital Territory and Northern Territory). In accordance with AASB 1049 (Appendix A) and the ABS GFS Manual (2005, p. 256), the general government sector is defined as the 'institutional sector comprising all government units and non-profit institutions controlled and mainly financed by government'.
} 
$A A S B 1049$ requirements provides an indication on the extent to which $A A S B$ 1049 is perceived to be appropriate for public sector stakeholders' needs, and thus whether the harmonisation process has resulted in financial information that is perceived to be useful for the public sector.

Our paper fills a gap in the public sector accounting literature by providing insights into whether the harmonisation of GAAP and GFS has resulted in prescribed accounting treatments and information presentations that are considered appropriate for the public sector. Prior research on the appropriateness of differing accounting treatments and the presentation of financial statements has been predominantly normative in nature (e.g. Carnegie and Wolnizer, 1995; Challen, 2004; Barton, 2005; Carnegie and West, 2005). While there have been a few empirical studies comparing perceptions on the appropriateness of different accounting frameworks adopted in Australia, most of the studies focused on the application of GAAP-based accrual principles (e.g. Jones and Puglisi, 1997; Andriani et al., 2010). One exception is Kober et al. (2010) who surveyed public sector users and preparers to compare their perceptions of cash-based, GAAPbased and GFS-based systems. However, Kober et al. (2010) focused their comparison on broad decision-making contexts (e.g. information for assessing a department's performance, and for decisions on the allocation of resources) and thus cannot facilitate comparisons with $A A S B$ 1049, which prescribes accounting treatments and presentations for specific financial items (e.g. the treatment of doubtful debts).

The remainder of the paper is structured as follows. The next section provides background on recent developments in public sector accounting in Australia. This then leads to the prior literature section, which summarises the research on decision usefulness of GAAP and GFS, as well as the debate relating to specific accounting treatment and presentation differences between the GAAP-based and GFS-based systems. This is followed by sections detailing the research design, results and a discussion of the results. The paper concludes with a summary of our findings, limitations of the research and avenues for future research.

\section{Background}

\subsection{Development of public sector accounting in Australia}

The development of accounting standards for the public sector can be traced back to the establishment of the Public Sector Accounting Standards Board (PSASB) in 1983, under the former Australian Accounting Research Foundation. Guided by the 'sector neutral' philosophy, the PSASB and the AASB jointly developed a set of Australian accounting standards (the former AAS series) applicable to both the private and the public sectors. In the 1990s, three accounting standards specific to the public sector were issued. These were $A A S$ 27 Financial Reporting by Local Government; AAS 29 Financial Reporting by Government Departments; and AAS 31 Financial Reporting by Government. 
However, these standards reflected characteristics of private sector standards and thus were criticised as being irrelevant to the public sector (Ryan, 1998; Barton, 2002, 2005, 2009; Newberry, 2003; Carnegie and West, 2005; Wise, 2006). The sector neutral approach was further strengthened when, in 2000, under the Federal Government's Corporate Law Economic Reform Program, the standard-setting role of the PSASB was taken over by the reconstituted AASB.

Historically, the GAAP-based accounting standard AAS 31 required federal, state and territory governments to prepare whole of government financial statements, with financial information about the general government sector only disclosed in notes to the accounts. However, federal, state and territory governments were also required to comply with the 'Uniform Presentation Framework' (UPF). ${ }^{2}$ Unlike $A A S 31$, the UPF requires the preparation of general government sector budget financial statements and requires that these be prepared on the basis of GFS. GFS is an International Monetary Fund government accounting system. Federal, state and territory governments adopted the Australian version of GFS prepared by the Australian Bureau of Statistics (ABS).

GAAP and GFS information serves different purposes. GAAP information is primarily for general-purpose financial reporting, whereas GFS information is for government macroeconomic decision-making, analysis of fiscal policies and national statistics purposes. The two sets of information are therefore prepared on the basis of different accounting and economic concepts (ABS, 2005; Barton, 2007). The GFS system employs the concept of flows and stocks for presenting government financial information. Transaction information (e.g. government tax revenue and expenditure) is distinguished from other economic flows (e.g. revaluation of assets). The financial information in the GFS system is generally presented in three main statements:

1 The GFS operating statement, which covers only transactions. Major fiscal aggregates of net operating balances and net lending/borrowing are presented for fiscal decision-making purposes. Other economic flows are presented in a separate statement.

2 The balance sheet, which presents assets, liabilities and contributed capital of government, highlighting the net worth of government.

3 The cash flow statement, which covers cash flows from operating, investing and financing activities of government, and measures the underlying cash balance for government.

\footnotetext{
${ }^{2}$ The UPF, which was introduced in 1991, is a budget reporting framework agreed to by the Australian federal, state and territory governments as a uniform basis for budget reporting, so as to enhance the transparency and comparability of budget financial statements across governments.
} 


\subsection{Harmonisation of GAAP and GFS}

Criticisms were levelled at the existence of different sets of financial information prepared on the basis of different accounting systems for measuring government financial performance. For example, Barton $(2005,2010)$ highlighted the confusion posed by the existence of two sets of accrual accounting and budgeting systems that provide two sets of substantially different financial results in his reviews of the Commonwealth budgetary accounting system.

In 2002, at the request of the Heads of federal and state Treasuries, the Financial Reporting Council issued a directive to the AASB to pursue the harmonisation of GAAP and GFS in order to address the confusion created by the two sets of statements and to better meet public sector users' information needs (Challen and Jeffery, 2003). The harmonisation process resulted in the issue of an accounting standard in 2006, which solely addressed the financial reporting of general government sector (AASB 1049 Financial Reporting of General Government Sector by Governments). This standard was subsequently replaced by $A A S B$ 1049 Whole of Government and General Government Sector Financial Reporting in $2007 .^{3}$ For the first time, the general government sector was recognised as a reporting entity, enabling the preparation of separate financial statements for this sector. With the release of $A A S B 1049$ and the harmonisation of international accounting standards, the three public sector accounting standards $(A A S$ 27, AAS 29 and AAS 31) were withdrawn in 2008.

The UPF was then amended to incorporate the requirements of $A A S B 1049$. However, it was not the intention of the federal, state and territory governments to make UPF fully consistent with $A A S B$ 1049. The UPF still maintains some of the fiscal aggregates considered by governments as essential to the transparency of budget reporting. The UPF (2008, p. 4) highlights that,

Rather than replacing the UPF with the new accounting standard, the framework was updated to align with AASB 1049... Aligning the framework with AASB 1049 was not intended to create a UPF that complies with all the reporting requirements of AASB 1049 ... Instead, the revised UPF allows jurisdictions to utilise the framework as the base set of statements and add additional relevant information in order to comply with AASB 1049.

The harmonisation process highlights the governments' commitment to narrow the gap between GAAP and GFS. However, it does not fundamentally resolve the controversial issues on information usefulness for the public sector (Barton, 2010).

In the pursuance of the harmonisation of GAAP and GFS, standard-setters were required to consider both the benefits and costs of any harmonised

\footnotetext{
${ }^{3}$ The International Public Sector Accounting Standards Board (IPSASB) has also been working on the convergence project and other ongoing public sector accounting issues, which may have implications for future public sector standard-setting in Australia.
} 
standard, so that the benefits derived from the information provided exceed the costs of doing so (AASB, 2004; Plummer et al., 2007; Baber and Gore, 2008). Consequently, based on this benefit-cost analysis, AASB 1049 is designed to deliver the benefits of improved information usefulness and comparability (AASB 1049, Preface and Objective sections) by maintaining GAAP principles as the foundation, but incorporating various key GFS classifications of financial items and fiscal aggregates. For example, the operating statement maintains the GAAP classification of operating results, as well as the GFS classification of transactions and other economic flows. Where GFS measures of key fiscal aggregates differ from the measures in accordance with $A A S B$ 1049, the standard requires a reconciliation of the two different measures. Hence, $A A S B 1049$ still establishes GAAP as the primary basis for accounting treatments.

Following the introduction of $A A S B 1049$ and the revised UPF, the state and territory governments prepared the first single set of whole of government as well as the general government sector budget financial reports (2008-2009) in a presentation format consistent with the requirement of the revised UPF and $A A S B$ 1049. However, the federal government prepared the 2008-2009 budget financial statements on the basis of GFS, with adjustments where the accounting standards provide a better accounting alternative.

The current practice by the federal government has been viewed favourably by researchers supporting GFS (e.g. Barton, 2009, 2010). Nevertheless, the differing practices between the federal government and those of the state and territory governments signal that there are still unresolved issues in the harmonisation of GAAP and GFS. This highlights the need for further research on the appropriateness of accounting treatments for the public sector, so as to provide insights into whether the harmonised accounting requirements will better meet users' needs.

\section{Prior literature}

GAAP-based accrual accounting has been applied in the Australian public sector since the public sector financial management reforms and is a result of the sector neutral approach to standard-setting. However, the appropriateness of applying GAAP-based principles to the public sector has been questioned in relation to the relevance, reliability and understandability (i.e. usefulness) of the resulting financial information (Kober et al., 2010). Prior literature has raised concerns about the relevance of applying business concepts to public sector accounting and reporting, without due consideration of the unique nature of the public sector (Barton, 1999, 2002, 2004; Newberry, 2001, 2003; Carnegie and West, 2005; Challen and Jeffery, 2005; Ellwood and Newberry, 2006). It is argued that private sector accounting concepts cannot simply be transferred to the public sector given its unique characteristics (such as providing public goods and social welfare, taxation power, the lack of market for government goods and services, and the collective decision-making process). 
Prior research investigating the appropriateness of applying GAAP-accrual accounting to the Australian public sector can be broadly separated into two streams of research. The first stream investigates the usefulness of GAAP in various decision contexts (Jones and Puglisi, 1997; Andriani et al., 2010; Kober et al., 2010). Jones and Puglisi (1997) surveyed department managers, at the state and Commonwealth government levels, about the usefulness of accrual accounting information for 19 internal decision contexts. Their results revealed 'fairly modest ratings of the relevance of accrual accounting to internal decision making' (Jones and Puglisi, 1997, p. 12). These fairly modest results, however, are likely to be attributable to the fact that Jones and Puglisi's (1997) survey was conducted in 1993-94, prior to the full adoption of accrual accounting. This is a point which, to some extent, is acknowledged by the authors in that they note that their results suggest an 'experience effect', with managers from government departments that prepared accrual-based financial reports rating accrual accounting as being more useful across certain decision contexts compared with managers from departments that did not prepare accrual-based financial reports.

Evidence of this experience effect is confirmed by the results of Andriani et al. (2010) and Kober et al. (2010), who report greater decision usefulness for GAAP-based accounting information. Andriani et al. (2010) surveyed departmental managers within the Western Australian public sector as to the perceived usefulness of both GAAP-based accounting information and cash-based accounting information across similar decision contexts as those used by Jones and Puglisi (1997). The results of Andriani et al. (2010) revealed that departmental managers perceived GAAP-based information as being significantly more useful in 15 of the 19 decision contexts than the cash-based information.

Kober et al. (2010) extended the earlier research by not only investigating the decision usefulness of GAAP-based accounting information compared with cash-based information, but also incorporating GFS-based accounting information. They surveyed Commonwealth and state government senior departmental managers (internal users), financial statement preparers, and external statement users from treasury and finance departments as well as public accounts committee members (external users). Respondents' opinions were sought on the usefulness of cash-based information, GAAP-based information, and GFS-based information across 12 decision contexts. Across the entire sample, GAAP-based information was found to be significantly more useful in decision-making in 11 of the 12 decision contexts compared with cash-based information and GFS-based information. Unsurprisingly, the only exception was in relation to assessing the cash flow needs of a department, where cash-based information was considered to be the most useful. When the authors conducted the analysis solely on users from treasury and finance departments as well as public accounts committee members, although GAAP-based accounting information still rated as being more useful, there were no statistically significant differences between GAAP-based information and GFS-based information on the previous 11 decision contexts. As noted by Kober et al. (2010), this provides support for the 
experience effect, in that users from treasury and finance departments as well as public accounts committee members are the people most likely to have had prior experience with GFS-based information.

The second stream of research, on which this study builds, focuses on the appropriateness of specific accounting treatments, in light of the unique nature of public sector operations. Within this stream of research, debate has centred on (i) the accounting for heritage and community assets where both historical and market values are irrelevant owing to these assets being public goods and non-exchangeable (Mautz, 1988; Pallot, 1990; Carnegie and Wolnizer, 1995; Barton, 2005; Carnegie and West, 2005); (ii) the misleading nature of the business concepts of revenue, accumulated surplus and equity to the public sector (Barton, 2004); (iii) the arbitrary and unreliable measurement of assets and liabilities as a result of using GAAP-accrual accounting (Conn, 1996; Carnegie and West, 2005); (iv) the capitalising and then depreciating of defence weapons under GAAP-accrual accounting methods, or expensing under GFS methods (Näsi et al., 2001; Challen and Jeffery, 2003); (v) the allowance for doubtful debts not being considered an economic event under GFS and, as such, not being reflected in financial reports (Youngberry, 2010); (vi) the presentation of information in the financial statements, with arguments being put forward that the presentation of financial statements under GFS is superior to that of GAAP financial statements (Barton, 2005, 2009, 2010; Youngberry, 2010).

While the above research presented various arguments in terms of the appropriate treatments of financial items and the presentation of financial information, none surveyed the stakeholders of public sector financial statements for their opinions on the matter. Because financial information should be useful for the needs of those who make decisions, the views of public sector stakeholders serve as an important input in the debate. This research aims to extend the current research by specifically surveying public sector stakeholders for their opinions on the appropriateness of specific accounting treatments and presentation of the financial statements.

\section{Research design}

\subsection{Questionnaire development}

A questionnaire was used to garner the views of public sector stakeholders on whether they believed it was more appropriate to use GAAP or GFS guidelines in the accounting treatment and presentation of a selection of financial items. The responses to this questionnaire were then used to compare against the requirements of $A A S B 1049$ to analyse the extent of alignment between what the standard prescribed and what stakeholders perceived as appropriate accounting treatments and presentations. 
The questionnaire comprised two sections. ${ }^{4}$ One section related to demographic information and the other section comprised questions that asked respondents to provide opinions on the appropriate accounting treatments and the presentation of selected financial items for the general government sector as a whole. ${ }^{5}$

The items examined in the questionnaire were selected based on a review of prior literature, government documents, government budget statements explanation notes and the Exposure Draft of $A A S B$ 1049. The items chosen were ones where major technical differences between GAAP and GFS treatments existed. These include items such as asset revaluations, gains or losses on disposal of assets, allowances for bad debts, acquisition of defence weapons, and goods and services tax, as well as different asset valuation bases. In total, nine financial items were incorporated into the questionnaire. There are also differences between GAAP and GFS in the presentation of financial items on the face of financial statements. For example, items representing key fiscal aggregates such as net operating balance from transactions, net worth, net lending or borrowing, and cash surplus are presented under GFS but not GAAP. Five items were incorporated into the questionnaire.

Table 1 lists the financial items examined in the questionnaire, outlining the nine 'accounting treatment' items and the five 'presentation' items. The table also describes the GAAP and GFS guidelines on the accounting treatment and presentation of these financial items and summarises the position adopted by $A A S B$ 1049.

In the questionnaire, the financial items were separately listed under two headings: accounting treatment and presentation. For each item, respondents were asked to indicate '... what was the appropriate accounting treatment or presentation for the general government sector as a whole'.

For each item, respondents were provided with four response options from which to choose and were instructed to select only one response. The first two response options specified possible alternative treatments/presentations. The alternatives provided were in accordance with GAAP guidelines, GFS guidelines or treatments identified from the literature. Respondents were not told which

\footnotetext{
${ }^{4}$ This study was part of a broader project on public sector financial reporting issues. Only questions relevant to the present study are reported here.

${ }^{5}$ The public sector comprises different institutional sectors, including the general government sector, public financial corporations and public non-financial corporations (ABS, 2005). Our survey only focused on the general government sector. This was for two reasons. First, the general government sector was recognised as a reporting entity for the first time following the release of $A A S B$ 1049, thus signalling the importance of this sector for accounting purposes. Second, the public sector accounting debate in the literature has been primarily directed at the general government sector because of its unique nature of this sector compared to other sectors (e.g. in the provision of public goods and social welfare).
} 


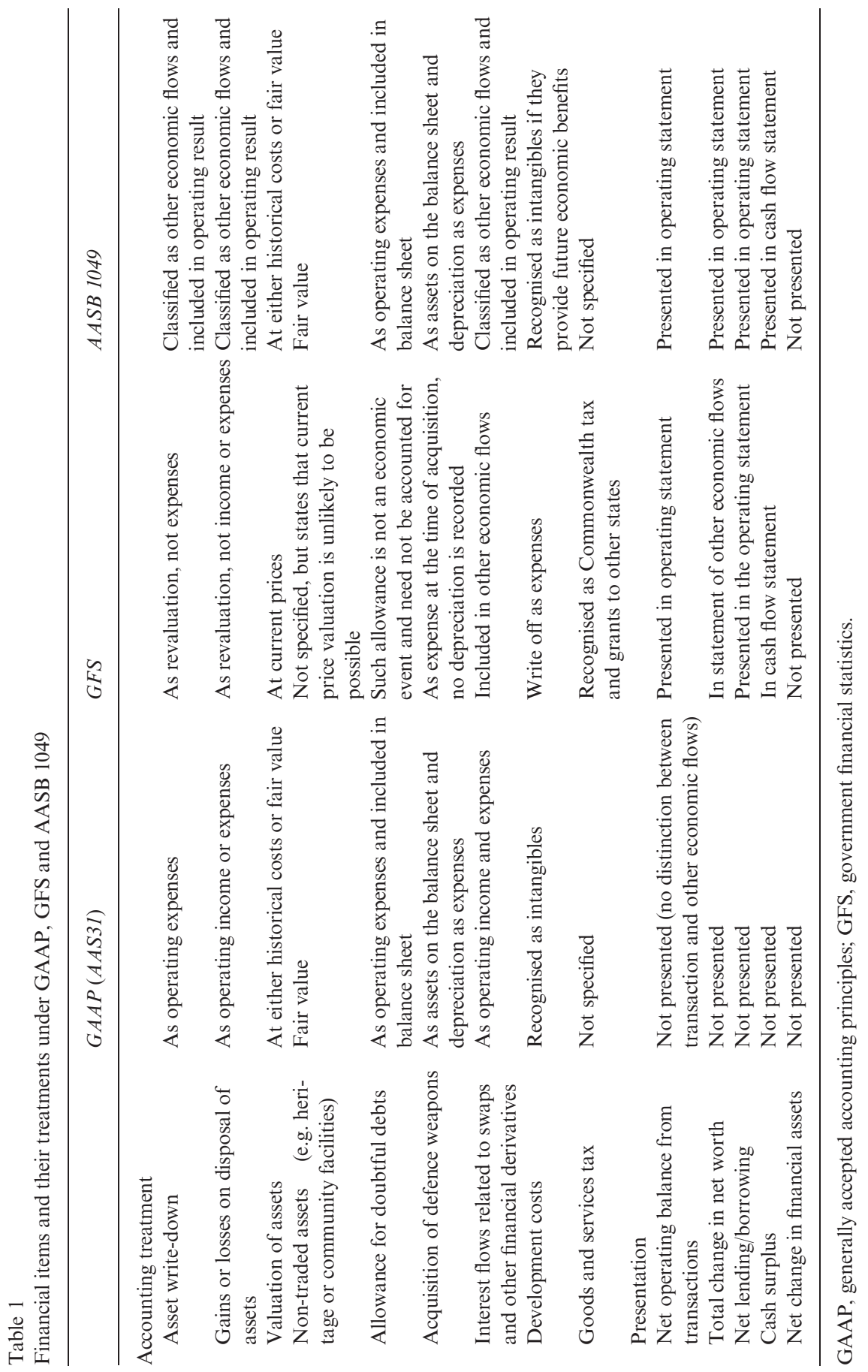

(C) 2012 The Authors

Accounting and Finance (C) 2012 AFAANZ 
alternative matched with which guidelines. The remaining two response options were labelled 'indifferent between the two alternatives' and 'unsure as to which alternative is more appropriate' ${ }^{6}$ By way of illustration, in the example of asset write-downs, the four response options provided to respondents were (i) as operating expenses; (ii) as revaluation, not expenses; (iii) indifferent between these two alternatives; and (iv) unsure which alternative is more appropriate. In this case, option (i) and option (ii) corresponded to GAAP guidelines and GFS guidelines, respectively.

To seek feedback on terminology and issues, and on the clarity of the questionnaire, the questionnaire was pilot-tested using a group of public sector senior managers who had responsibilities for accounting and reporting and academics who had familiarity with the operations of the public sector. The pilot-test did not result in any changes being required, suggesting that the task and the terminology used were manageable and understandable.

\subsection{Sample}

Public sector stakeholders from federal, state and territory governments were included in this study in order to gather the views of a broad cross-section of stakeholders. Questionnaires were mailed to representatives from governing bodies, senior managers of government departments and chief financial officers (CFOs) of government departments. Representatives from governing bodies were selected because governing bodies are frequently cited as the major parties who are interested in public sector financial reports (Anthony, 1978; Jones et al., 1985; AARF, 1990; Micallef et al., 1994; Mack and Ryan, 2006; ANAO, 2009). The governing bodies group of our study comprised government officials responsible for accounting, reporting and budgets in Treasury and Finance departments, and Public Accounts Committee members in federal, state and territory governments. Treasury and Finance departments are the main central agencies overseeing government accounting guidance and are involved in the preparation of government consolidated financial reports and budgets (Ryan, 1998, 1999; Mack and Ryan, 2006), whereas Public Accounts Committees are key bodies inquiring into government accounting matters. The senior managers of government departments comprised heads and deputy heads of departments. These senior managers were selected because individuals in these positions are expected to be responsible for providing financial data to central governments for the preparation of consolidated financial statements for the general government sector and the whole of government, as well as government budget statements

\footnotetext{
${ }^{6}$ Given the technical nature of the questions, these latter two options were included so as to avoid respondents being forced to select a treatment/presentation when they had no clear preference or were unsure of the different treatments/presentations. By incorporating these latter two options, we are also better able to gauge whether there was a clear preference between the alternative treatments/presentations.
} 
(ANAO, 2009). Public sector senior managers are likely to be interested in public sector consolidated statements as these statements inform managers of government bodies (Walker, 2009). Chief financial officers were also targeted as they are the key personnel who supply government financial information and have knowledge and expertise in public sector accounting issues.

The names and mailing addresses of the sample were obtained from parliamentary and government department websites. Questionnaires were initially distributed to 179 individuals in the governing bodies group; 231 senior managers in 110 departments in federal, state and territory governments, which substantially covers all government departments across Australia; and CFOs in 96 departments in federal, state and territory governments. ${ }^{7}$

Approximately 4 weeks after the initial distribution, a follow-up mail out was conducted. In total, 103 responses were received, representing a response rate of approximately 24 per cent. $^{8}$ A summary of the questionnaire distribution and responses is provided in Panel a of Table 2. Panel b provides a profile of the respondents. Approximately 72 per cent of the sample had accounting backgrounds. Respondents had worked in the public sector for an average of 17.8 years and, on average, had 11.5 years of managerial experience in the public sector, and 14 years in public sector financial management. Forty-six per cent of the sample had private sector experience.

\section{Results}

The results are presented in four sections. The first section presents the results of respondents' preferences as to the most appropriate accounting treatment for the financial items included in our questionnaire. The second section presents the results of respondents' preferences as to the most appropriate presentation of a set of financial items. The third section compares differences across respondent groups (i.e. CFOs, senior management and governing bodies) as well as across Commonwealth and state government levels. In the fourth section, we compare our results regarding respondents' preferred accounting treatments/presentations against the requirements of $A A S B$ 1049, thus providing insights into whether AASB 1049 has resulted in information that is perceived to be appropriate for the decision needs of the public sector.

The results of respondents' preferences for the appropriate accounting treatment and presentation of each financial item are presented in Table 3. The

\footnotetext{
${ }^{7}$ Only 96 departments were sampled as we were unable to identify the names of chief financial officers from the websites of some departments.

${ }^{8}$ We received notification from several government departments alerting us to the fact that they had chosen to provide a combined response rather than complete separate questionnaires. We have adjusted Table 2 and the response rate to reflect instances known to us.
} 
Table 2

(a) Sample information and (b) profile of respondents

\begin{tabular}{|c|c|c|c|c|}
\hline & Total & $\begin{array}{l}\text { Governing } \\
\text { bodiest }\end{array}$ & $\begin{array}{l}\text { Senior } \\
\text { management: }\end{array}$ & CFOsई \\
\hline \multicolumn{5}{|l|}{ (a) } \\
\hline Initial sample & 506 & 179 & 231 & 96 \\
\hline $\begin{array}{l}\text { Less: Survey returned as wrong } \\
\text { addresses/not in the positions/completed } \\
\text { wrong version of questionnaire/other } \\
\text { reasons }\end{array}$ & (32) & (18) & $(5)$ & (9) \\
\hline Less: Combined responses & (58) & (2) & $(48)$ & 0 \\
\hline Final sample & 424 & 159 & $178 \dagger$ & 87 \\
\hline Responses received & 103 & 28 & 16 & 59 \\
\hline $\begin{array}{l}\text { Response rate } \\
\text { (b) }\end{array}$ & $24.3 \%$ & $17.6 \%$ & $9.0 \%$ & $67.8 \%$ \\
\hline $\begin{array}{l}\text { Member of professional } \\
\text { accounting association }\end{array}$ & $72 \%$ & $57 \%$ & $50 \%$ & $84.5 \%$ \\
\hline Average public sector experience & 17.8 years & 16 years & 21.5 years & 17.5 years \\
\hline $\begin{array}{l}\text { Average public sector } \\
\text { managerial experience }\end{array}$ & 11.5 years & 10 years & 14.5 years & 11 years \\
\hline $\begin{array}{l}\text { Average public sector financial } \\
\text { management experience }\end{array}$ & 14 years & 11 years & 15.5 years & 14.5 years \\
\hline Private sector experience & $46 \%$ & $50 \%$ & $37.5 \%$ & $46 \%$ \\
\hline \multicolumn{5}{|l|}{ Employer } \\
\hline Commonwealth & $19.5 \%$ & $18 \%$ & $19 \%$ & $21 \%$ \\
\hline State/territory & $80.5 \%$ & $82 \%$ & $91 \%$ & $79 \%$ \\
\hline
\end{tabular}

$\dagger$ Governing bodies: comprises those officials responsible for accounting, reporting and budgets within Treasury and Finance departments, and Public Accounts Committee members at federal, state and territory governments. \$Senior management: comprises heads and deputy heads of departments. $\S$ CFOs: include chief financial officers or equivalent positions of government departments. \Combined responses refers to those departments that notified the researchers that they had provided a combined response rather than individual responses, and those department heads and deputy heads who passed their questionnaires to the CFO or finance personnel to respond. ††If departments provided a combined response, which appeared to be a common practice, it is possible that the final sample for senior management could be substantially lower.

treatments and presentations are presented in hierarchical order, with the treatments and presentations selected by the largest percentage of respondents shown first. Alternative 1 represents the treatment or presentation preferred by most respondents.

\subsection{Accounting treatments}

As can be seen from Table 3, there is a mix of preferences for GAAP or GFS treatments depending on the underlying financial items. Consistent with GAAP, the majority of respondents selected the following accounting treatments 


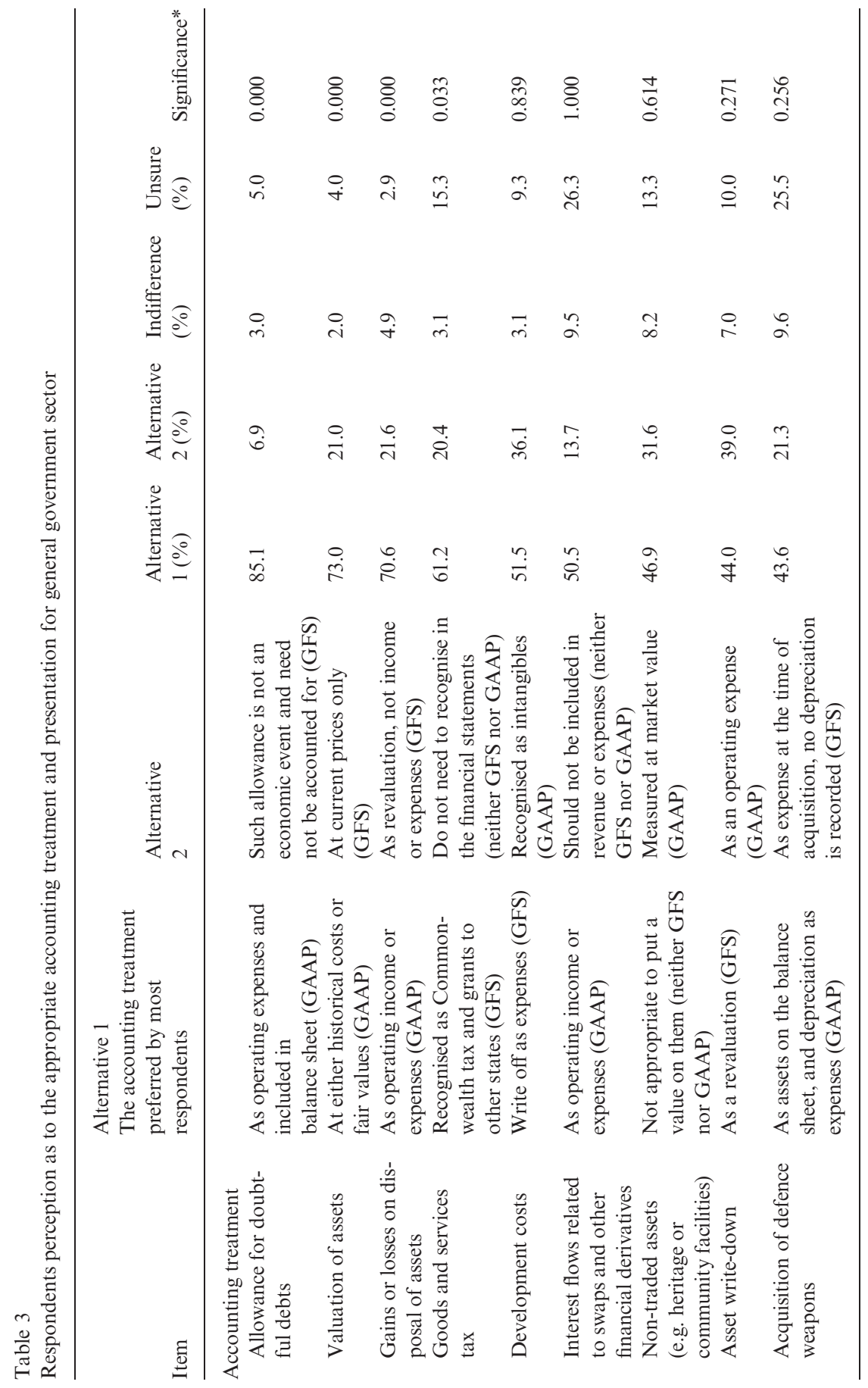

(C) 2012 The Authors

Accounting and Finance (C) 2012 AFAANZ 


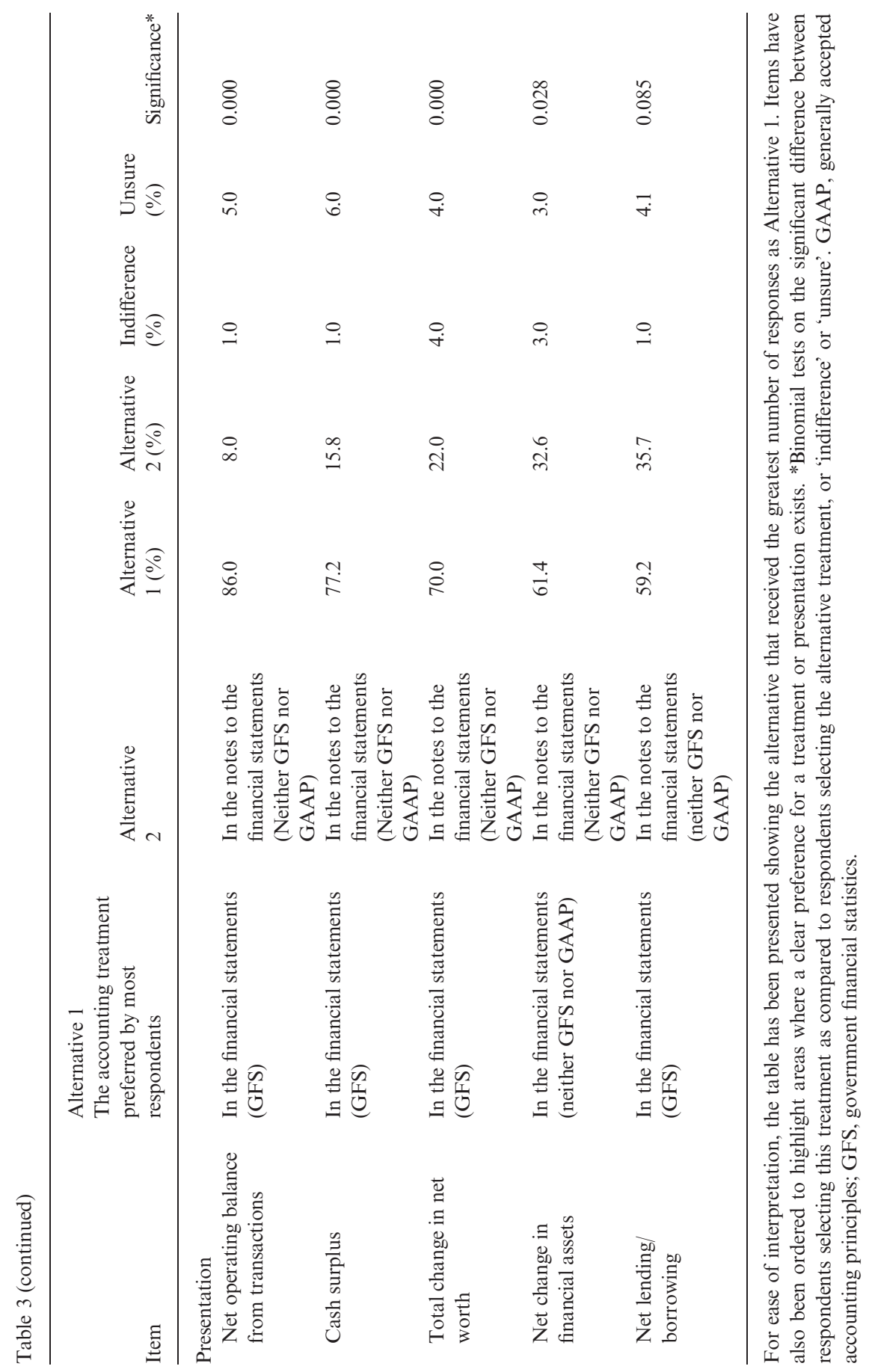

(C) 2012 The Authors

Accounting and Finance (C) 2012 AFAANZ 
(numbers in parentheses indicate the percentage of respondents selecting this treatment):

1 That the allowance for doubtful debts be written off as an operating expense and recognised as a contra-asset in the balance sheet ( 85.1 per cent)

2 That assets be valued at either historical costs or fair values (73.0 per cent)

3 That gains (losses) on the disposal of assets be treated as operating income (expenses) (70.6 per cent)

4 That interest flows related to swaps and other financial derivatives be treated as operating income or expenses (50.5 per cent)

5 That the acquisition of defence weapons be treated as an asset on the balance sheet and be depreciated (43.6 per cent).

Table 3 highlights that the respondents' preferences for the GAAP treatments were statistically significant ( $p<0.001$ ) for (i) allowances for doubtful debts, (ii) valuations of assets and (iii) gains or losses on disposal of assets. This indicates a strong level of support for the GAAP treatment for these three items. It is interesting to note that for interest flows related to swaps and the acquisition of defence weapons, approximately a quarter of the respondents were unsure of the most appropriate accounting treatment for these two items. This suggests that the accounting treatments for interest flows related to swaps and for the acquisition of defence weapons are unclear to public sector stakeholders and warrant further enquiry by standard-setters as to the appropriate treatment.

The treatments that were consistent with GFS and selected by a majority of respondents are as follows (numbers in parentheses indicate the percentage of respondents selecting this treatment):

1 Goods and services tax be recognised as Commonwealth tax and grants to other states (61.2 per cent)

2 Development costs be written off as an expense (51.5 per cent)

3 Asset write-downs be recognised as a revaluation (44.0 per cent).

The preference for the goods and services tax to be considered a Commonwealth tax and grants to other states was the only GFS-preferred treatment that was statistically significant, indicating strong support for this treatment option. While the majority of respondents selected the GFS treatment for development costs and asset write-downs, there were also a large proportion of respondents selecting the GAAP treatments for these two items, 36.1 per cent and 39.0 per cent, respectively, indicating that there is no clear consensus by respondents on the accounting treatment of these items and that further investigation is warranted.

For the treatment of non-traded assets (e.g. heritage or community assets), the majority of respondents (46.9 per cent) indicated that they thought it was not appropriate to place a value on them. This response is inconsistent with both 
GAAP and GFS, but is consistent with prior researchers' views regarding the specific nature of such public sector assets and that their financial value is irrelevant for public sector management and decisions (Carnegie and Wolnizer, 1995; Barton, 2002).

\subsection{Presentation}

As can be seen from Table 3, there is a strong preference by respondents for the selected financial items to be shown in the financial statements as opposed to the notes to the financial statements. That is, respondents thought it appropriate for the key government fiscal aggregates of net operating balance from transactions, cash surplus, total change in net worth, net change in financial assets, and net lending/borrowing to be disclosed in the financial statements. These preferences were all significant at $p<0.10$, indicating a strong preference for such disclosure in the financial statements. The presentation in the financial statements of the government fiscal aggregates of net operating balance from transactions, cash surplus, total change in net worth, and net lending/borrowing is required under the GFS system. However, the presentation of the net change in financial assets is not required under either GFS or GAAP.

\subsection{Differences among respondent groups}

Although not reported, we checked to see whether the preference for treatment and presentation was consistent across the three respondent groups. ${ }^{9}$ On all but two occasions, the three respondent groups consistently exhibited a preference for the same treatment or presentation. The two exceptions related to the treatment of development costs and asset write-downs. On both instances, it was the CFOs who exhibited a difference in opinion, and on both occasions, they had a slight preference ( 5 per cent difference or less) for the GAAP treatment over the GFS treatment preferred by the majority of senior managers and representatives of governing bodies. That is, the CFOs showed a slight preference for recognising development costs as an intangible asset and recognising asset write-downs as an operating expense, both of which are in accordance with GAAP treatments. These two preferences for GAAP treatments over the GFS treatments by CFOs may relate to CFOs professional accounting background, in which they would have been trained in, and become familiar with, the GAAP accounting treatments.

Further supplementary analysis on the percentage of respondents from each stakeholder group selecting Alternative 1 (the treatment or presentation preferred by the majority of respondents) revealed that (i) on each occasion when Alternative 1 was consistent with the GAAP treatment, the preference for the

\footnotetext{
${ }^{9}$ Statistical analysis was not conducted owing to small sample sizes.
} 
GAAP treatment was the strongest by CFOs and (ii) for the presentation in financial statements, with one exception (total change in net worth), the preference for the GFS presentation was strongest among governing bodies.

Taken together, this general preference for GAAP treatments by CFOs and GFS presentations by governing bodies is consistent with the experience effect originally noted in Jones and Puglisi (1997) and discussed in Kober et al. (2010). CFOs are probably the most familiar of the three stakeholder groups with GAAP accounting treatments and as such have a stronger preference for these treatments compared with the other two stakeholder groups (governing bodies and senior management). Likewise, governing bodies are the most experienced of the stakeholder groups with GFS treatments and presentations and consequently have the strongest preference for GFS presentations compared with the other two stakeholder groups (CFOs and senior management).

Although our results show evidence of an experience effect, it is significant to note that first preferences for treatments and presentations are largely consistent, with only the two exceptions previously noted, across the three stakeholder groups. This highlights that respondents are not necessarily wedded to one particular accounting paradigm but are generally willing to select the treatment or presentation (either GAAP or GFS) they perceive as being most appropriate for each particular item.

Supplementary testing was also conducted to see whether respondents from the different levels of government (i.e. Commonwealth vs. state governments) responded differently. The analysis revealed there were no differences in terms of preferred treatment or presentation between respondents from state and federal levels.

\subsection{Comparison of respondents' preferences to the requirements of AASB 1049}

To gain insights into the perceived usefulness of $A A S B$ 1049, we compare respondents' views with the requirements of the standard. The results in Table 4 are ordered so as to first present those items where there was agreement between respondents' opinions and the treatment required under AASB 1049.

As can be seen from Table 4, the results are mixed with regard to whether respondents' preferences for particular accounting treatments are consistent with those of $A A S B$ 1049. For five items, the views of the majority of respondents are in line with the treatments required under $A A S B$ 1049. These items are (i) treating bad debts as an operating expense and placing the allowance for doubtful debts in the balance sheet, (ii) the valuation of assets at either historical costs or fair value, (iii) recognising gains or losses on the disposal of assets as operating income or expenses (respectively), (iv) recognising interest flows related to swaps and other financial derivatives as operating income or expenses and (v) recognising defence weapons as assets on the balance sheet and depreciating them. These preferences are also consistent with GAAP-based accounting treatments, but this 


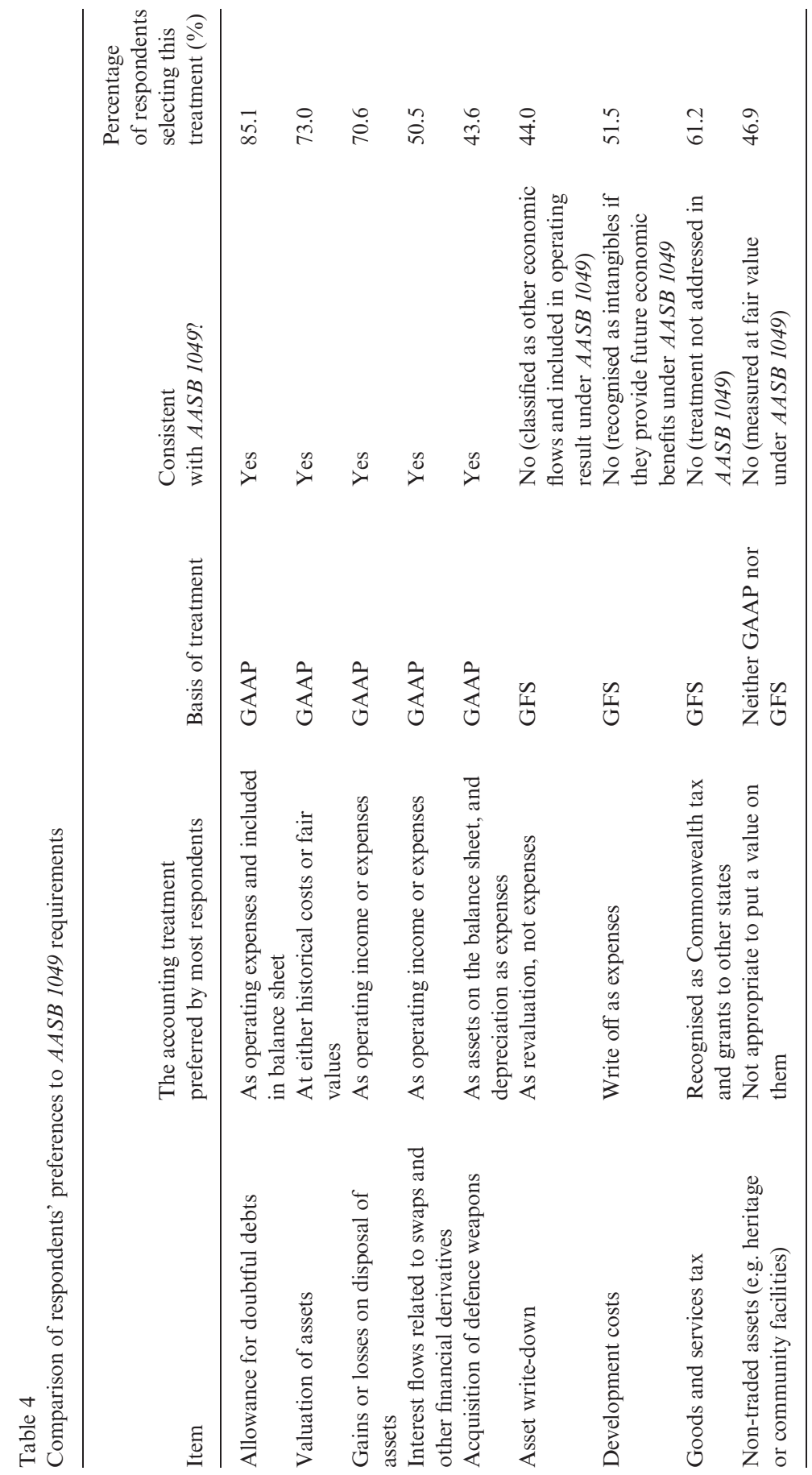




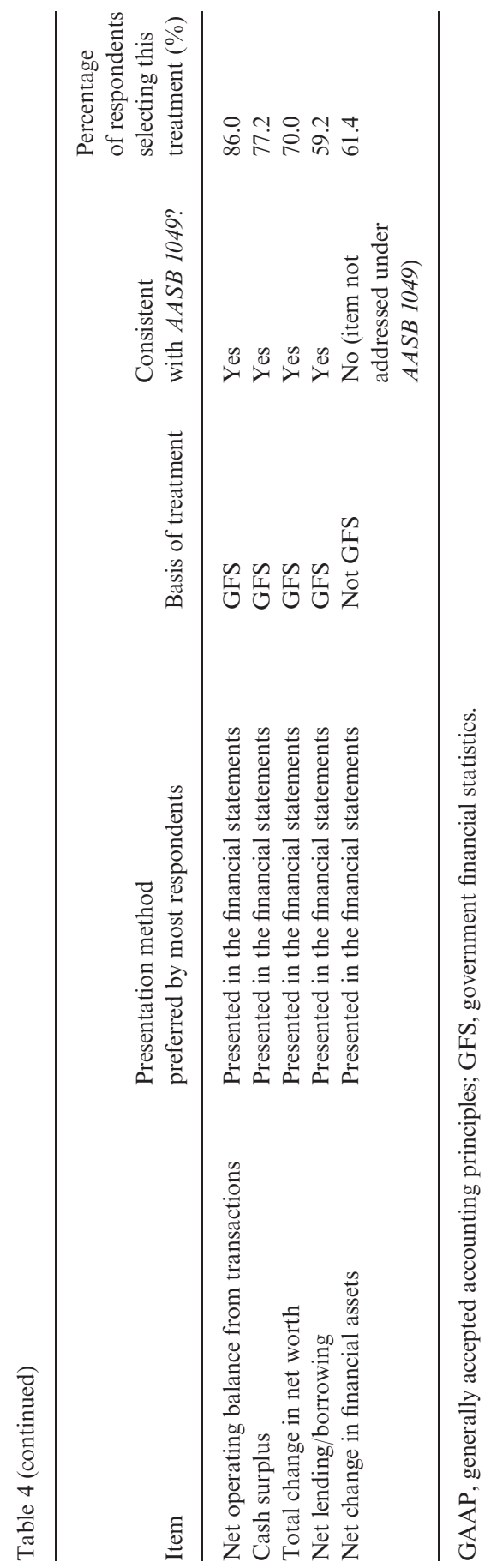


is not surprising as $A A S B 1049$ is primarily based on GAAP, with modifications to incorporate GFS features.

As revealed in Table 4, when the majority of respondents preferred a non GAAP-based treatment for an item, this was inconsistent with the treatment of the item under $A A S B$ 1049. On three of these four occasions, the majority of respondents selected treatments that corresponded to the GFS treatment, these being (i) the recording of asset write-downs as revaluations and not expenses, (ii) writing off development costs as expenses, and (iii) goods and services tax being recognised as Commonwealth tax and grants to states. In relation to the treatment of asset write-downs and of development costs, $A A S B 1049$ adheres to the GAAP treatment of these items (i.e. asset write-downs are included in the operating results while development costs are capitalised as intangible assets if they provide future economic benefits). With regard to the treatment of goods and services taxes, $A A S B 1049$ is silent. The other occasion when the majority of respondents' views were inconsistent with the treatment under $A A S B 1049$ related to the treatment of non-traded assets (e.g. heritage or community facilities). The majority of respondents believed it was not appropriate to place a value on these assets, which is inconsistent with the treatment under both GAAP and GFS. Again, $A A S B 1049$ follows the GAAP treatment of requiring measurement at fair value.

In contrast to respondents' views on the treatment of various items, respondents' preferences regarding the presentation of government fiscal aggregates are largely consistent with those required by $A A S B$ 1049. $A A S B 1049$ requires presentation, on the face of financial statements, of GFS fiscal aggregates, but with slight modification, including net operating balance from transactions, total change in net worth, net lending/borrowing and cash surplus. As can be seen from Table 4, the majority of respondents agreed to these presentations as harmonised under $A A S B$ 1049. It is interesting to observe that the majority of respondents also favoured the presentation in the financial statements of the net change in financial assets, which is not required by $A A S B 1049$.

\section{Discussion}

Our findings reveal a strong consensus view on the presentation of government fiscal aggregates on the face of the financial statements, largely providing support for the stance adopted under $A A S B$ 1049. The respondents' views support prior researchers' advocacy for the usefulness of GFS information and to present this information in the financial statements (Challen, 2004; Barton, 2005). The results thus reinforce the notion that information required by the public sector is different from that of the private sector (Barton, 1999; Newberry, 2001; Ellwood and Newberry, 2006), and support the move of the standard-setter to align the presentation of public sector financial statements with the budget statements to enhance the relevance and comparability of information. 
While it is important to present information in a useful way, the underlying measurement of financial items is equally crucial. Despite the agreement on the presentation items, the results of our survey show that, for accounting treatments for the selected items, respondents' views are not necessarily aligned to one basis of accounting (either GAAP or GFS), nor are they necessarily consistent with $A A S B 1049$ treatments. The results highlight that GAAP-based accounting treatments are not necessarily regarded as the most appropriate approach in producing financial information for the public sector. For five of the nine items, the majority of respondents selected the GAAP-based treatment as being the most appropriate. However, for three items, the majority of respondents selected the GFS treatment as being the most appropriate, and for one item, a treatment that fell neither under GAAP nor GFS was selected by the majority as being the most appropriate. The fact that, for four of the nine items, the majority of respondents did not select GAAP-based treatments, reiterates the concerns about transposing business concepts to the public sector (Pallot, 1990; Barton, 1999, 2002; Newberry, 2001, 2003; Carnegie and West, 2005).

The mixed views on the appropriateness of accounting treatments, with GAAP-based treatments considered appropriate for some items and GFS-based treatments regarded as better for other items, highlight that respondents are likely to favour the accounting treatments that they consider to be conceptually sound, no matter whether it is GAAP-based or GFS-based. This is evidenced in comments written by respondents such as:

Which accounting system (GAAP vs. GFS) is not as important as making sure that the system is consistent and relevant to government.

Both GFS and GAAP have useful measures that enable users to measure the performance of government and assist government in decision-making.

These comments and our findings appear to support the convergence of GAAP and GFS for the public sector.

As noted previously, the results of our survey highlight that GAAP-based accounting treatments are not necessarily regarded by respondents as the most appropriate approach to producing financial information for the general government sector. Hence, under the current standard-setting framework, the use of GAAP-based principles in measuring the government fiscal aggregates appears to be at odds with the intended purposes of harmonisation to improve the usefulness of public sector financial information. The fundamental problem of how to account for items specific to the public sector still remains even though significant efforts have been directed at harmonisation. This raises concern about how useful the harmonised standard is, and the effect of the harmonised standard remains to be seen.

Even though GAAP-based and GFS-based accounting methods are derived from different conceptual foundations, respondents' preferences highlight the complementary nature of the accounting-based GAAP treatments and the 
economic-based GFS treatments. Consistent with Whittington's (1977) harmonised views of accounting and economics, respondents' choice of preferred accounting treatments and presentation support the idea of harmonising the two systems in the preparation of a single set of general government sector financial statements. However, the fact that the preferred accounting treatments that are reflected in the AASB 1049 are largely GAAP-based may suggest that the current harmonised view by standard-setters of accounting and economics is perhaps realised only to the extent of the presentation of financial information rather than the underlying accounting treatments.

Furthermore, prior literature has raised concerns about the tension between accounting professionals and economists in the development of public sector accounting rules, with accounting professionals being seen as dominating the standard-setting process for the public sector (Guthrie, 1990; Ryan, 1998, 1999; Christensen, 2003; Ryan et al., 2007). Given that none of the preferred GFSbased accounting treatments from our survey are reflected in the so-called harmonised standard, our results suggest that the domination of the accounting professionals' perspective continues.

\section{Conclusion}

Prior to the release of $A A S B 1049$, the Australian public sector was required to prepare two different sets of financial statements (one set based on GAAP principles and the other based on GFS principles) that provided different financial results. $A A S B 1049$ was developed to harmonise the GAAP and GFS systems. In releasing $A A S B$ 1049, the AASB sought to address the confusion caused by having different sets of financial statements and aimed to provide accounting information that better met the needs of the public sector (Youngberry, 2010).

This paper examines the extent to which the requirements of $A A S B 1049$ match with public sector stakeholders' perceptions of appropriate accounting treatments and presentations for selected financial items. This analysis provides insights into whether $A A S B 1049$ is perceived to be appropriate for public sector stakeholders' needs, and thus whether the harmonisation process has resulted in financial information that is perceived to be useful for the public sector.

Empirical evidence was obtained through a survey of public sector stakeholders regarding their perceptions of the appropriate accounting treatments and presentations for a set of financial items. The results reveal that respondents' perceptions of the presentation of government fiscal aggregates are largely consistent with those adopted by AASB 1049. Thus, there appears to be support for the standard's potential benefits in enhancing the usefulness of the presentation format of financial information for the public sector. On the other hand, respondents have different preferences for accounting treatments of financial items. The results indicate that respondents do not have a particular preference for either the GAAP or the GFS systems, suggesting that the main criterion is the most 
appropriate treatment for particular items, rather than a preference for either system. However, the preferred accounting treatments by respondents are not all reflected in the standard. This highlights that accounting treatments, particularly for those items specific to the public sector, remain controversial.

Our results reveal consensus views for the presentation of financial aggregates similar to the GFS system. This view, together with the preferences for using GAAP-based and GFS-based treatments for different financial items, highlights the complementary nature of accounting-based and economic-based conceptual foundations, and the potential benefits of harmonising the two conceptually different systems for public sector accounting and budgeting. However, our results do identify some gaps between respondents' preferences and the requirements of $A A S B$ 1049, suggesting that further review is required in the harmonisation process.

As with any survey-based research, this research is not without its limitations. The results of this research relate specifically to the selected items shown in Table 1. While this is a representative list of contentious issues regarding the treatment and presentation of financial items for the public sector, it is by no means an exhaustive list. Investigation into other items may yield differing insights. Our sample is also limited to individuals representing governing bodies, senior management and CFOs. It would be insightful to extend this research to encompass other stakeholder groups, such as government audit offices, government statistics offices and accounting professional bodies. In-depth analysis into the reasons for stakeholders' views through interviews or experimental methods would also be a worthwhile avenue for future research. Knowledge regarding the underlying components of the government fiscal aggregates as required by $A A S B$ 1049 would also further assist the understanding of the usefulness of information produced under $A A S B$ 1049. As the current $A A S B 1049$ is developed within the GAAP framework, future research directed at the relevance of GAAP or GFS as the primary basis for the harmonisation of the two systems would provide valuable insights into harmonisation issues.

\section{References}

Andriani, Y., R. Kober, and J. Ng, 2010, Decision usefulness of cash and accrual information: public sector managers' perceptions, Australian Accounting Review 20, 144-153.

Anthony, R., 1978. Financial Accounting in Nonbusiness Organizations: An Exploratory Study of Conceptual Issues (Financial Accounting Standards Board, Norwalk, CT).

Australian Accounting Research Foundation (AARF), 1990, Statement of Accounting Concepts SAC 2 Objective of General Purpose Financial Reporting, August.

Australian Accounting Standards Board (AASB), 2004, Framework for the Preparation and Presentation of Financial Statements, July.

Australian Bureau of Statistics (ABS), 2005, Australian System of Government Finance Statistics, Concepts, Sources and Methods, 5514.0 (Commonwealth of Australia, Canberra). 
Australian National Audit Office (ANAO), 2009, Preparation of Financial Statements by Public Sector Entities, Better Practice Guide, June.

Baber, W.R., and A.K. Gore, 2008, Consequences of GAAP disclosure regulation: evidence from municipal debt issues, The Accounting Review 83, 565-591.

Barton, A., 1999, Public and private sector accounting - the non-identical twins, Australian Accounting Review 9, 22-31.

Barton, A., 2002, Accrual Accounting in Government: A Review of its Applications, Achievements and Problems, and Proposals for Reform, Paper presented at Annual Research Lecture in Government Accounting, The Australian National University and CPA Australia, Canberra.

Barton, A., 2004, How to profit from Defence: a study in the misapplication of business accounting to the public sector in Australia, Financial Accountability \& Management 20, 281-304.

Barton, A., 2005, Professional accounting standards and the public sector - a mismatch, Abacus 41, 138-158.

Barton, A., 2007, Accrual accounting and budgeting systems issues in Australian governments, Australian Accounting Review 17, 38-50.

Barton, A., 2009, The use and abuse of accounting in the public sector financial management reform program in Australia, Abacus 45, 221-248.

Barton, A., 2010, The GFS system - the answer to the government's financial management information problems?, Paper presented at CPA Australia - Australian National Audit Office - Australian National University Annual Research Lecture in Public Sector Accounting, Canberra.

Carnegie, G.D., and B.P. West, 2005, Making accounting accountable in the public sector, Critical Perspective on Accounting 16, 905-928.

Carnegie, G., and P. Wolnizer, 1995, The financial value of cultural, heritage and scientific collections: an accounting fiction, Australian Accounting Review 5, 131-147.

Challen, D., 2004, Harmonisation of accounting standards and the implications for the public sector, Paper presented at the CPA Public Sector Congress, Canberra.

Challen, D., and C. Jeffery, 2003, Harmonisation of government finance statistics and generally accepted accounting principles, Australian Accounting Review 13, 48-53.

Challen, D., and C. Jeffery, 2005, Definition of the reporting entity, Australian Accounting Review 35, 71-78.

Christensen, M., 2003, Without reinventing the wheel: business accounting applied to the public sector, Australian Accounting Review, 13, 22-27.

Commonwealth of Australia, 2008, Uniform Presentation Framework, April, Canberra.

Conn, N., 1996, Reservations about Governments Producing Balance Sheets, Australian Journal of Public Administration 55, 82-85.

Ellwood, S., and S. Newberry, 2006, A bridge too far: a common conceptual framework for commercial and public benefit entities, Accounting and Business Research 36, 19-32.

Guthrie, J., 1990, Current developments in public sector accounting and auditing standard setting in Australia, in: J. Guthrie, L. Parker, D. Shand, eds., The Public Sector: Contemporary Readings in Accounting and Auditing (Harcourt Brace, Jovanovich, Sydney), 238-244.

Jones, S., and N. Puglisi, 1997, The relevance of AAS29 to the Australia public sector: a cause for doubt?, Abacus, 33, 115-132.

Jones, D., R. Scott, L. Kimbro, and R. Ingram 1985, The Needs of Users of Governmental Financial Reports, Governmental Accounting Standards Board, October.

Kober, R., J. Lee, and J. Ng, 2010, Mind your accruals: perceived usefulness of financial information in the Australian public sector under different accounting systems, Financial Accountability \& Management, 26, 267-298. 
Mack, J., and C. Ryan, 2006, Reflections on the theoretical underpinnings of the generalpurpose financial reports of Australian government departments, Accounting, Auditing and Accountability Journal 19, 592-612.

Mautz, R., 1988, Monuments, mistakes, and opportunities, Accounting Horizons, June, 123-128.

Micallef, F., P. Sutcliffe, and P. Doughty, 1994, Financial Reporting by Governments, Australian Accounting Research Foundation, Discussion Paper No.21.

Näsi, S., K. Hansen, and H. Hefzi, 2001, Off-balance sheet assets in central governments: are they unique or are they really assets?, Journal of Interdisciplinary Studies, 14, $137-154$.

Newberry, S., 2001, Public-sector accounting: a common reporting framework?, Australian Accounting Review 11, 2-7.

Newberry, S., 2003, Sector neutrality and NPM 'incentives': their use in eroding the public sector, Australian Accounting Review 13, 28-34.

Pallot, J., 1990, The nature of public assets: a response to Mautz, Accounting Horizons, June, 79-85.

Plummer, E., P. Hutchison, and T. Patton, 2007, GASB No. 34's governmental financial reporting model: evidence on its information relevance, The Accounting Review 82, 205-240.

Ryan, C., 1998, The introduction of accrual reporting policy in the Australian public sector: an agenda setting explanation, Accounting, Auditing and Accountability Journal 11, $518-539$.

Ryan, C., 1999, Australian public sector financial reporting: a case of cooperative policy formulation, Accounting, Auditing and Accountability Journal 12, 561-582.

Ryan, C., J. Guthrie, and R. Day, 2007, Politics of financial reporting and the consequences for the public sector, Abacus 43, 474-487.

Walker, R.G., 2009, Public sector consolidated statements - an assessment, Abacus 45, 171-220.

Whittington, G., 1977, Accounting and economics, in: B. Carsberg, T Hope, eds., Current Issues in Accounting (Philip Allan, Oxford), 192-212.

Wise, V., 2006, Cross-sector transfer of consolidated financial reporting - conceptual concerns, Australian Journal of Public Administration 65, 62-73.

Youngberry, T., 2010, Response to Barton (2010) The GFS system - the answer to the government's financial management information problems?, Paper presented at CPA Australia - Australian National Audit Office - Australian National University Annual Research Lecture in Public Sector Accounting, Canberra.

(C) 2012 The Authors

Accounting and Finance (C) 2012 AFAANZ 